Published in final edited form as:

J Ultrasound Med. 2006 August ; 25(8): 947-956.

\title{
A Novel Algorithm for Comprehensive Fetal Echocardiography using 4D Ultrasound and Tomographic Imaging
}

\author{
Jimmy Espinoza, MD ${ }^{1,2}$, Juan Pedro Kusanovic, MD1 ${ }^{1}$, Luís F. Gonçalves, MD ${ }^{1,2}$, Jyh Kae \\ Nien, MD ${ }^{1}$, Sonia Hassan, MD ${ }^{2}$, Wesley Lee, MD ${ }^{3}$, and Roberto Romero, MD ${ }^{1,4}$ \\ 1 Perinatology Research Branch, NICHD, NIH, DHHS, Bethesda, Maryland and Detroit, Michigan \\ 2 Wayne State University, Department of Obstetrics and Gynecology, Detroit, Michigan \\ 3 William Beaumont Hospital, Royal Oak, Michigan
}

4 Wayne State University, Center for Molecular Medicine and Genetics, Detroit, Michigan

\begin{abstract}
Objective-Tomographic ultrasound imaging (TUI) is a new display modality that allows simultaneous visualization of up to eight parallel anatomical planes. This study was designed to determine the role of a novel algorithm combining spatiotemporal image correlation (STIC) and TUI to visualize standard fetal echocardiography planes.
\end{abstract}

\begin{abstract}
Methods-Volume datasets from fetuses with and without congenital heart defects (CHD) were examined with a novel algorithm that allows simultaneous visualization of the three-vessel and trachea view, the four-chamber view, and outflow tracts. Visualization rates for these planes as well as ductal arch and five-chamber view were calculated.
\end{abstract}

Results-1) 227 volume datasets from fetuses without ( $\mathrm{n}=138)$ and with ( $\mathrm{n}=14)$ CHD were reviewed; 2) among normal fetuses, the four-chamber view, five-chamber view, ductal arch, threevessel and trachea view, left outflow tract and short axis of the aorta were visualized in 99\% (193/195), 96.9\% (189/195), $98.5 \%$ (192/195), 88.2\% (172/195), 93.3\% (182/195), and 87.2\% $(170 / 195)$ of the volume datasets, respectively; 3$)$ these views were visualized in $85 \%(17 / 20), 80 \%$ $(16 / 20), 65 \%(13 / 20), 55 \%(11 / 20), 55 \%(11 / 20)$, and $70 \%$ (14/20) of the volume datasets, respectively, from fetuses with CHD; and 4) simultaneous visualization of the short axis of the aorta, three-vessel and trachea view, left outflow tract and four-chamber view was obtained in $78 \%$ $(152 / 195)$ of the volume datasets from fetuses without CHD and in 40\% (8/20) of those with CHD.

Conclusion-The three-vessel and trachea view, the four-chamber view, and both outflow tracts can be simultaneously visualized using a novel algorithm combining STIC and TUI.

\section{Keywords}

Algorithm; 3D; 4D; three-dimensional; four-dimensional; STIC; spatiotemporal; congenital heart disease; spatiotemporal; prenatal diagnosis; fetal echocardiography

\section{Introduction}

Congenital heart disease remains one of the leading causes of infant mortality. ${ }^{1}$ However, only 6 to $35 \%$ of heart defects are identified in the prenatal period. ${ }^{2-12}$ This has been largely attributed to both the complexity of the fetal heart and the high degree of expertise required

\footnotetext{
Address correspondence to: Roberto Romero, M.D., Perinatology Research Branch, NICHD, NIH, DHHS, Wayne State University/ Hutzel Women's Hospital, 3990 John R, Box 4, Detroit, MI 48201, Telephone (313) 993-2700, Fax: (313) 993-2694, e-mail: warfiela@mail.nih.gov.
} 
for a thorough examination of this fetal organ. ${ }^{13-15}$ Accumulating evidence indicates that prenatal diagnosis of some congenital heart diseases, including transposition of the great arteries, hypoplastic left heart syndrome and coarctation of the aorta can reduce neonatal morbidity and mortality. ${ }^{16-19}$ Thus, the development of new algorithms designed to facilitate the examination of the fetal heart, could potentially increase the detection rates of these congenital heart diseases and reduce perinatal morbidity and mortality associated with them.

Two-dimensional ultrasound has traditionally relied on standard anatomic planes for a thorough examination of the fetal heart, including the four-chamber view, three-vessel and trachea view, and the left and right outflow tracts. ${ }^{20-25}$ Several reports $26-73$ indicate that three-dimensional ultrasound (3DUS) and 4DUS with spatio temporal image correlation (STIC) can facilitate the visualization of these planes. Thus, 3D and 4D fetal echocardiography could potentially reduce the operator dependency.

Recently, TUI has been introduced as a new display technology for 3DUS and 4DUS. This modality allows for the simultaneous display of up to eight parallel planes whose distance can be adjusted for a better visualization of anatomic planes. Thus, TUI allows the visualization of multiple sections of a beating heart at the same time. An "overview image" is shown on the upper left corner (Figure 1). This view shows a plane orthogonal to the slices, and parallel lines demarcate the position of the slices within the volume dataset. The user can adjust the number and position of the slices with specific software controls. TUI has been used for the examination of the fetal heart ${ }^{74,75}$ and other fetal organs. ${ }^{76}$ However, the simple use of parallel planes to the four-chamber view of the heart does not allow for the visualization of the long axis view of the left outflow tract and the short axis view of the aorta, which are considered part of an integral examination of the fetal heart. ${ }^{20-22}$ Moreover, the untargeted use of TUI allows for the simultaneous display of anatomic planes with and without diagnostic value (Figure 1). This study was designed to determine the value of a new algorithm, using STIC and TUI, in the visualization of the standard planes used in fetal echocardiography.

\section{Material and Methods}

Four-dimensional volume datasets of the fetal heart were acquired with transverse sweeps through the fetal chest in 152 patients examined at our ultrasound unit between December 1, 2003 and December 31, 2004. Volume datasets from fetuses without $(n=138)$ and with $(n=14)$ congenital heart defects, with postnatal confirmation (by post-natal echocardiography, surgery or during autopsy), were included in the study. Examinations were performed with STIC (Voluson 730 Expert, release BTO4, GE Healthcare, Milwaukee, Wisconsin) using hybrid mechanical and curved array transducers (RAB 4-8P, RAB 4-8L, RAB 2-5P, RAB 2-5L). Acquisition time ranged from 7.5 to 15 seconds and the angle of acquisition ranged between 20 and 40 degrees depending on fetal motion and gestational age. Patients were examined between 14 and 41 weeks of gestation (median 24 3/7 weeks; interquartile range: 20 6/7 to 28 $6 / 7$ weeks). All patients were enrolled in research protocols approved by the Institutional Review Board of the National Institute of Child Health and Human Development (NICHD/ NIH/DHHS) and by the Human Investigation Committee of Wayne State University (Detroit, Michigan). All women signed a written informed consent before participating in the study.

After removal of patient identifiers, examinations were retrospectively reviewed offline using the 4DView software version 5.0 (4D VIEW 5.0, General Electric Medical Systems, Kretztechnik, Zipf, Austria). A maximum of two volume datasets per patient (one acquired with B-mode imaging and one with color Doppler) were included in the study. Preference was given to volume datasets acquired between 16 and 24 weeks of gestation, when available, and the volume dataset considered by the investigator to be of highest quality was selected. Volume datasets with the following characteristics were considered to be of high quality: 1) the fetal 
spine was positioned between 3 and 9 o'clock, minimizing the possibility of shadowing from the ribs or spine; and 2) minimal or no motion artifact were observed on the sagittal plane. Volume datasets that did not contain the upper mediastinum were excluded from the study.

\section{Description of the algorithm}

All volume datasets were displayed using the multiplanar modality, which allows simultaneous display of images in three orthogonal planes (panels A, B and C). The following algorithm was used for examination of the fetal heart:

1. The volume datasets were adjusted to display the four-chamber view in panel $\mathrm{A}$, where the fetal aorta was aligned with the crux of the heart in the vertical plane. The reference dot was positioned in the aorta allowing the visualization of the coronal view of the descending aorta in panel $\mathrm{C}$ (Figure 2).

2. In panel $\mathrm{C}$ the image was rotated to display the aorta in a vertical position, when necessary. This allowed for the visualization of the longitudinal view of the ductal arch in panel B (Figure 3).

3. In panel $\mathrm{A}$, the reference dot was moved to the crux of the heart and the TUI option was selected. This allowed for the simultaneous visualization of the longitudinal view of the ductal arch in the first panel and eight perpendicular planes to this plane (Figure 1). Only three planes were selected using the "Slices" option, including the plane that crosses the reference dot (which is labeled with an asterisk in the software), one plane to the left ("-1") and another one to the right ("+1"). These images were magnified using the four panel "display format" option (Figure 4).

4. In panel $\mathrm{A}$, the image was moved until the reference dot was positioned in the center of the aorta. The "Adjust" option was selected to align the " -1 " plane with the ductal arch and the " +1 " plane with the external edge of the aorta. (Figure 5). This allowed for the simultaneous visualization of the longitudinal view of the ductal arch in panel $\mathrm{A}$, the three-vessel and trachea view in panel B, the five chamber view in panel $\mathrm{C}$ and the four-chamber view in panel D.

5. The "Rotation Y" was selected by clicking on the bar, and the five chamber view was rotated by scrolling on the $\mathrm{Y}$ axis until the left outflow tract was visualized in panel B (this was generally accomplished with a right sided rotation between 8 to 22 degrees). This allowed for the simultaneous visualization of the short axis of the aorta in panel A, the three-vessel and trachea view in panel B, the long axis of the left outflow tract on panel $\mathrm{C}$ and the four-chamber view on panel D (Figure 6). In some cases, the image was optimized by moving the reference dot above the aortic valve in panel C.

Four video clips illustrating the simplicity of the algorithm described above are available for download from the journal's website.

\section{Statistical analysis}

The visualization rates of the: 1) longitudinal view of the ductal arch; ${ }^{21}$ 2) five-chamber view; 20,213 ) three-vessel and trachea view; 77 4) four-chamber view; ${ }^{15,20,21,78} 5$ ) long axis of the left outflow tract; ${ }^{15,20,21,78}$ and 6) short axis of the aorta, ${ }^{20}$ (right outflow tract) as well as the simultaneous visualization of the last four planes, were determined using the novel algorithm. Contingency tables were used to compare the visualization rates of these anatomic planes between volume datasets obtained with B mode and those obtained with color Doppler in fetuses with and without heart defects. A $p<0.05$ was considered significant. Statistical analysis was performed with SPSS 12.0 for Windows (SPSS, Chicago, IL). 


\section{Results}

Two hundred and twenty seven volume datasets were reviewed from fetuses with and without congenital heart defects. B-mode and color Doppler ultrasound were used to acquire 59.9\% (136/227) and $40.1 \%(91 / 227)$ of the 4D volume datasets, respectively. Volume datasets of poor imaging quality [5.3\% (12/227)] were excluded from analysis.

Table 1 displays the visualization rates of the standard sonographic planes in volume datasets, acquired with B mode or color Doppler, from fetuses without heart defects. Overall, a normal four-chamber view, five-chamber view, longitudinal view of the ductal arch, three-vessel and trachea view, left outflow tract and short axis were visualized in 99\% (193/195), 96.9\% (189/195), 98.5\% (192/195), 88.2\% (172/195), 93.3\% (182/195), and 87.2\% (170/195) of the volume datasets, respectively. The visualization rates of these planes were higher in fetuses between 20 to 30 weeks of gestational age than in those at less than 20 weeks and those above 30 weeks. However, these differences were statistically significant only for the visualization of the five-chamber view. (Table 2)

Table 3 displays the visualization rates for the standard sonographic planes in volume datasets, acquired with B mode or color Doppler, from fetuses with heart defects. Overall, a fourchamber view, five-chamber view, longitudinal view of the ductal arch, three-vessel and trachea view, left outflow tract and short axis were clearly visualized in $85 \%(17 / 20), 80 \%$ (16/20), 65\% (13/20), 55\% (11/20), 55\% (11/20), and 70\% (14/20) of the volume datasets, respectively. These heart defects included: transposition of the great arteries $(n=2)$, tetralogy of Fallot $(n=1)$, atrioventricular canal $(n=2)$, hypoplastic left heart $(n=2)$, coarctation of the aorta $(n=1)$, left isomerism $(n=1)$, double outlet right ventricle $(n=1)$, pulmonary stenosis with intact ventricular septum $(n=1)$, ventricular septal defects $(n=2)$, and rhabdomyoma $(n=1)$.

The simultaneous visualization of the three-vessel and trachea view, the four-chamber view and both outflow tracts were obtained in $78 \%(152 / 195)$ of the volume datasets from fetuses without heart defects and in 40\% (8/20) of those from fetuses with heart defects. Among fetuses without heart defects, the visualization rates of the three-vessel and trachea view and the simultaneous visualization the three-vessel and trachea view, the four-chamber view and both outflow tracts were significantly higher when using volume datasets obtained with color Doppler than when using volume dataset obtained with B-mode (Table 1).

\section{Discussion}

Our study demonstrates that a novel algorithm using a combination of 4DUS and TUI allowed for visualization of the standard planes for fetal echocardiography in most fetuses with and without heart defects.

Our results are consistent with recent reports indicating that TUI can facilitate the examination of the fetal heart. ${ }^{74,75}$ Moreover, our visualization rates for the four-chamber view, left and right ventricular outflow tracts and three-vessel and trachea views are similar to those previously reported by scrolling through the volume datasets from the abdomen to the upper mediastinum. ${ }^{56}$ However, our algorithm further allows for visualization of the long axis view of the left outflow tract and the short axis view of the aorta, ${ }^{20}$ which can not be properly visualized with planes that are parallel to the four-chamber view. This algorithm provides a simple method for simultaneous display of the three-vessel and trachea view, the four-chamber view, as well as both outflow tracts, while limiting the number of planes to those with diagnostic value.

The sonographic planes proposed for 2D fetal echocardiography have been derived from planes used by pediatric cardiologists. ${ }^{21}$ Allan et al. reported a seminal study correlating sonographic 
planes used in fetal echocardiography and anatomic sections of the fetal thorax in aborted fetuses from 12 to 28 weeks of gestation, designed to reproduce these sonographic planes. ${ }^{79}$ The authors reported that: 1) the apex of the fetal heart is tilted more cephalad than in the postnatal period making more difficult to obtain the long axis view of the left ventricle; and 2) the sonographic plane most easily obtained in the fetus was the four-chamber view of the heart. 79 Thus, due to its relative simplicity, the four-chamber view has been used as a screening method for congenital heart defects for over two decades, ${ }^{80-86}$ and has been included as part of the basic fetal cardiac examination by several regulatory bodies. ${ }^{15,87-89}$ In contrast, the examination of the outflow tracts has been regarded only as part of "an extended basic cardiac examination"15,87-89, despite accumulating evidence indicating that the evaluation of the outflow tracts can substantially increase the detection rates of congenital heart disease. ${ }^{22-}$ $25,90,91$

A thorough examination of the fetal cardiac anatomy has been proposed to include transverse views (abdomen at the level of the stomach, four-chamber view, five-chamber view, threevessel view and the transverse aortic arch), long-axis views (short axis of the left ventricle, tricuspid/aortic cut, long axis of the duct, long axis of the aortic arch and the inferior and superior vena cava) and "angulated views" (long axis of the left ventricle). ${ }^{20}$ In addition, five "short-axis views", including the three-vessel and trachea view, has been proposed as a screening method for a comprehensive fetal echocardiography. ${ }^{77}$ These sonographic planes can be easily obtained by re-slicing volume datasets of the fetal heart obtained with 3D and 4D ultrasound as demonstrated by our algorithm. Previous algorithms allow for the simultaneous display of both outflow tracts, ${ }^{50}$ for the identification of the nature of vascular structures by rotating around $\mathrm{X}$-and $\mathrm{Y}$-axis from reference images obtained in a transverse sweep through the fetal chest, ${ }^{63}$ or for the identification of heart defects using color or power Doppler and STIC. ${ }^{62,66,67}$

The lower visualization rates of the sonographic planes used in fetal echocardiography among fetuses with heart defects may reflect abnormal spatial relationships. We have used volume datasets obtained with 4DUS with STIC of the fetal heart and its connecting vessels. However, the proposed algorithm could possibly be applied to volume datasets obtained with 3DUS using other commercially available software with tomographic display. In addition, color Doppler may also improve the diagnostic value of the proposed algorithm as demonstrated by the higher visualization rates of the three-vessel and trachea view as well as the simultaneous display of the three-vessel and trachea view, the four-chamber view and both outflow tracts, among fetuses without heart defects.

The introduction of new display modalities such as the TUI coupled with novel algorithms, such as the one proposed herein, may further simplify the examination of the fetal heart and could reduce the operator dependency that characterizes $2 \mathrm{D}$ fetal echocardiography. The inability to obtain standard planes with this or previously reported $50,62,63,75,92$ algorithms should raise the possibility of an underlying heart defect. Prospective studies are required to determine the ability of these algorithms as screening methods for the identification of congenital heart defects.

\section{Supplementary Material}

Refer to Web version on PubMed Central for supplementary material.

\section{Acknowledgements}

This research was supported by the Intramural Research Program of the National Institute of Child Health and Human Development, NIH, DHHS. 


\section{References}

1. Boneva RS, Botto LD, Moore CA, et al. Mortality associated with congenital heart defects in the United States: trends and racial disparities, 1979-1997. Circulation 2001;103:2376-2381. [PubMed: 11352887]

2. Stoll C, Alembik Y, Dott B, Roth PM, De Geeter B. Evaluation of prenatal diagnosis of congenital heart disease. Prenat Diagn 1993;13:453-461. [PubMed: 8372071]

3. Crane JP, LeFevre ML, Winborn RC, et al. A randomized trial of prenatal ultrasonographic screening: impact on the detection, management, and outcome of anomalous fetuses. The RADIUS Study Group. Am J Obstet Gynecol 1994;171:392-399. [PubMed: 8059817]

4. Rustico MA, Benettoni A, D'Ottavio G, et al. Fetal heart screening in low-risk pregnancies. Ultrasound Obstet Gynecol 1995;6:313-319. [PubMed: 8590200]

5. Buskens E, Grobbee DE, Frohn-Mulder IME, et al. Efficacy of Routine Fetal Ultrasound Screening for Congenital Heart Disease in Normal Pregnancy. Circulation 1996;94:67-72. [PubMed: 8964120]

6. Todros T, Faggiano F, Chiappa E, et al. Accuracy of routine ultrasonography in screening heart disease prenatally. Gruppo Piemontese for Prenatal Screening of Congenital Heart Disease. Prenat Diagn 1997;17:901-906. [PubMed: 9358568]

7. Fernandez CO, Ramaciotti C, Martin LB, Twickler DM. The four-chamber view and its sensitivity in detecting congenital heart defects. Cardiology 1998;90:202-206. [PubMed: 9892769]

8. Stoll C, Alembik Y, Dott B, et al. Evaluation of prenatal diagnosis of congenital heart disease. Prenat Diagn 1998;18:801-807. [PubMed: 9742567]

9. Grandjean H, Larroque D, Levi S. The performance of routine ultrasonographic screening of pregnancies in the Eurofetus Study. Am J Obstet Gynecol 1999;181:446-454. [PubMed: 10454699]

10. Klein SK, Cans C, Robert E, Jouk PS. Efficacy of routine fetal ultrasound screening for congenital heart disease in Isere County, France. Prenat Diagn 1999;19:318-322. [PubMed: 10327135]

11. Garne E, Stoll C, Clementi M. Evaluation of prenatal diagnosis of congenital heart diseases by ultrasound: experience from 20 European registries. Ultrasound Obstet Gynecol 2001;17:386-391. [PubMed: 11380961]

12. Jaeggi ET, Sholler GF, Jones OD, Cooper SG. Comparative analysis of pattern, management and outcome of pre- versus postnatally diagnosed major congenital heart disease: a population-based study. Ultrasound Obstet Gynecol 2001;17:380-385. [PubMed: 11380960]

13. Hunter S, Heads A, Wyllie J, Robson S. Prenatal diagnosis of congenital heart disease in the northern region of England: benefits of a training programme for obstetric ultrasonographers. Heart 2000;84:294-298. [PubMed: 10956294]

14. Tegnander E, Eik-Nes SH. The examiner's ultrasound experience has a significant impact on the detection rate of congenital heart defects at the second trimester fetal examination. Ultrasound Obstet Gynecol 2004;24:217. [PubMed: 15329970]

15. The International Society of Ultrasound in Obstetrics and Gynecology Guidelines. Cardiac screening examination of the fetus: guidelines for performing the "basic" and "extended basic" cardiac scans. Ultrasound Obstet Gynecol 2006;27:107-113. [PubMed: 16374757]

16. Mahle WT, Clancy RR, McGaurn SP, Goin JE, Clark BJ. Impact of prenatal diagnosis on survival and early neurologic morbidity in neonates with the hypoplastic left heart syndrome. Pediatrics 2001;107:1277-1282. [PubMed: 11389243]

17. Franklin O, Burch M, Manning N, et al. Prenatal diagnosis of coarctation of the aorta improves survival and reduces morbidity. Heart 2002;87:67-69. [PubMed: 11751670]

18. Tworetzky W, McElhinney DB, Reddy VM, et al. Improved surgical outcome after fetal diagnosis of hypoplastic left heart syndrome. Circulation 2001;103:1269-1273. [PubMed: 11238272]

19. Bonnet D, Coltri A, Butera G, et al. Detection of transposition of the great arteries in fetuses reduces neonatal morbidity and mortality. Circulation 1999;99:916-918. [PubMed: 10027815]

20. Allan L. Technique of fetal echocardiography. Pediatr Cardiol 2004;25:223-233. [PubMed: 15360115]

21. Chaoui R. The examination of the normal fetal heart using two-dimensional fetal echocardiography. 2003:141-149. 
22. Carvalho JS, Mavrides E, Shinebourne EA, Campbell S, Thilaganathan B. Improving the effectiveness of routine prenatal screening for major congenital heart defects. Heart 2002;88:387-391. [PubMed: 12231598]

23. Bromley B, Estroff JA, Sanders SP, et al. Fetal echocardiography: accuracy and limitations in a population at high and low risk for heart defects. Am J Obstet Gynecol 1992;166:1473-1481. [PubMed: 1595802]

24. Benacerraf BR. Sonographic detection of fetal anomalies of the aortic and pulmonary arteries: value of four-chamber view vs direct images. AJR Am J Roentgenol 1994;163:1483-1489. [PubMed: 7992752]

25. Comstock $\mathrm{CH}$. What to expect from routine midtrimester screening for congenital heart disease. Semin Perinatol 2000;24:331-342. [PubMed: 11071374]

26. Deng J, Gardener JE, Rodeck CH, Lees WR. Fetal echocardiography in three and four dimensions. Ultrasound Med Biol 1996;22:979-986. [PubMed: 9004421]

27. Meyer-Wittkopf M, Cook A, McLennan A, et al. Evaluation of three-dimensional ultrasonography and magnetic resonance imaging in assessment of congenital heart anomalies in fetal cardiac specimens. Ultrasound Obstet Gynecol 1996;8:303-308. [PubMed: 8978001]

28. Nelson TR, Pretorius DH, Sklansky M, Hagen-Ansert S. Three-dimensional echocardiographic evaluation of fetal heart anatomy and function: acquisition, analysis, and display. J Ultrasound Med 1996;15:1-9. [PubMed: 8667477]

29. Zosmer N, Jurkovic D, Jauniaux E, et al. Selection and identification of standard cardiac views from three-dimensional volume scans of the fetal thorax. J Ultrasound Med 1996;15:25-32. [PubMed: 8667480]

30. Chang FM, Hsu KF, Ko HC, et al. Fetal heart volume assessment by three-dimensional ultrasound. Ultrasound Obstet Gynecol 1997;9:42-48. [PubMed: 9060130]

31. Sklansky MS, Nelson TR, Pretorius DH. Usefulness of gated three-dimensional fetal echocardiography to reconstruct and display structures not visualized with two-dimensional imaging. Am J Cardiol 1997;80:665-668. [PubMed: 9295008]

32. Levental M, Pretorius DH, Sklansky MS, et al. Three-dimensional ultrasonography of normal fetal heart: comparison with two-dimensional imaging. J Ultrasound Med 1998;17:341-348. [PubMed: 9623470]

33. Nelson TR. Three-dimensional fetal echocardiography. Prog Biophys Mol Biol 1998;69:257-272. [PubMed: 9785942]

34. Sklansky MS, Nelson TR, Pretorius DH. Three-dimensional fetal echocardiography: gated versus nongated techniques. J Ultrasound Med 1998;17:451-457. [PubMed: 9669304]

35. Sklansky MS, Nelson T, Strachan M, Pretorius D. Real-time three-dimensional fetal echocardiography: initial feasibility study. J Ultrasound Med 1999;18:745-752. [PubMed: 10547106]

36. Guerra FA, Isla AI, Aguilar RC, Fritz EG. Use of free-hand three-dimensional ultrasound software in the study of the fetal heart. Ultrasound Obstet Gynecol 2000;16:329-334. [PubMed: 11169308]

37. Levi S, Cos-Sanchez T. Fetal echocardiography volume mode (3 dimensions). J Gynecol Obstet Biol Reprod (Paris) 2000;29:261-263. [PubMed: 10804367]

38. Meyer-Wittkopf M, Rappe N, Sierra F, Barth H, Schmidt S. Three-dimensional (3-D) ultrasonography for obtaining the four and five-chamber view: comparison with cross-sectional (2-D) fetal sonographic screening. Ultrasound Obstet Gynecol 2000;15:397-402. [PubMed: 10976481]

39. Scharf A, Geka F, Steinborn A, et al. 3D real-time imaging of the fetal heart. Fetal Diagn Ther 2000;15:267-274. [PubMed: 10971079]

40. Bega G, Kuhlman K, Lev-Toaff A, Kurtz A, Wapner R. Application of three-dimensional ultrasonography in the evaluation of the fetal heart. J Ultrasound Med 2001;20:307-313. [PubMed: 11316308]

41. Deng J, Yates R, Birkett AG, et al. Online motion-gated dynamic three-dimensional echocardiography in the fetus--preliminary results. Ultrasound Med Biol 2001;27:43-50. [PubMed: 11295269]

42. Meyer-Wittkopf M, Cooper S, Vaughan J, Sholler G. Three-dimensional (3D) echocardiographic analysis of congenital heart disease in the fetus: comparison with cross-sectional (2D) fetal echocardiography. Ultrasound Obstet Gynecol 2001;17:485-492. [PubMed: 11422968] 
43. Meyer-Wittkopf M, Cole A, Cooper SG, Schmidt S, Sholler GF. Three-dimensional quantitative echocardiographic assessment of ventricular volume in healthy human fetuses and in fetuses with congenital heart disease. J Ultrasound Med 2001;20:317-327. [PubMed: 11316309]

44. Michailidis GD, Simpson JM, Karidas C, Economides DL. Detailed three-dimensional fetal echocardiography facilitated by an Internet link. Ultrasound Obstet Gynecol 2001;18:325-328. [PubMed: 11778990]

45. Arzt W, Tulzer G, Aigner M. [Real time 3D sonography of the normal fetal heart--clinical evaluation]. Ultraschall Med 2002;23:388-391. [PubMed: 12514755]

46. Deng J, Yates R, Sullivan ID, et al. Dynamic three-dimensional color Doppler ultrasound of human fetal intracardiac flow. Ultrasound Obstet Gynecol 2002;20:131-136. [PubMed: 12153663]

47. Deng J, Sullivan ID, Yates R, et al. Real-time three-dimensional fetal echocardiography--optimal imaging windows. Ultrasound Med Biol 2002;28:1099-1105. [PubMed: 12401378]

48. Deng J, Richards R. Dynamic three-dimensional gray-scale and color Doppler ultrasound of the fetal heart for dynamic diagnosis. Ultrasound Obstet Gynecol 2002;20:209. [PubMed: 12153679]

49. DeVore GR, Falkensammer P, Sklansky MS, Platt LD. Spatiotemporal image correlation (STIC): new technology for evaluation of the fetal heart. Ultrasound Obstet Gynecol 2003;22:380-387. [PubMed: 14528474]

50. Goncalves LF, Lee W, Chaiworapongsa T, et al. Four-dimensional ultrasonography of the fetal heart with spatiotemporal image correlation. Am J Obstet Gynecol 2003;189:1792-1802. [PubMed: 14710117]

51. Herberg U, Goldberg H, Breuer J. Dynamic free-hand three-dimensional fetal echocardiography gated by cardiotocography. Ultrasound Obstet Gynecol 2003;22:493-502. [PubMed: 14618663]

52. Jurgens J, Chaoui R. Three-dimensional multiplanar time-motion ultrasound or anatomical M-mode of the fetal heart: a new technique in fetal echocardiography. Ultrasound Obstet Gynecol 2003;21:119-123. [PubMed: 12601830]

53. Maulik D, Nanda NC, Singh V, et al. Live three-dimensional echocardiography of the human fetus. Echocardiography 2003;20:715-721. [PubMed: 14641376]

54. Meyer-Wittkopf M, Hofbeck M. Two- and three-dimensional echocardiographic analysis of congenital heart disease in the fetus. Herz 2003;28:240-249. [PubMed: 12756481]

55. Sklansky M. New dimensions and directions in fetal cardiology. Curr Opin Pediatr 2003;15:463-471. [PubMed: 14508293]

56. Vinals F, Poblete P, Giuliano A. Spatio-temporal image correlation (STIC): a new tool for the prenatal screening of congenital heart defects. Ultrasound Obstet Gynecol 2003;22:388-394. [PubMed: 14528475]

57. Abuhamad A. Automated multiplanar imaging: a novel approach to ultrasonography. J Ultrasound Med 2004;23:573-576. [PubMed: 15154522]

58. Acar P, Dulac Y, Taktak A, Villaceque M. [Real time 3D echocardiography in congenital heart disease]. Arch Mal Coeur Vaiss 2004;97:472-478. [PubMed: 15214550]

59. Bhat AH, Corbett VN, Liu R, et al. Validation of volume and mass assessments for human fetal heart imaging by 4-dimensional spatiotemporal image correlation echocardiography: in vitro balloon model experiments. J Ultrasound Med 2004;23:1151-1159. [PubMed: 15328429]

60. Bhat AH, Corbett V, Carpenter N, et al. Fetal ventricular mass determination on three-dimensional echocardiography: studies in normal fetuses and validation experiments. Circulation 2004;110:10541060. [PubMed: 15326076]

61. Brekke S, Tegnander E, Torp HG, Eik-Nes SH. Tissue Doppler gated (TDOG) dynamic threedimensional ultrasound imaging of the fetal heart. Ultrasound Obstet Gynecol 2004;24:192-198. [PubMed: 15287059]

62. Chaoui R, Hoffmann J, Heling KS. Three-dimensional (3D) and 4D color Doppler fetal echocardiography using spatio-temporal image correlation (STIC). Ultrasound Obstet Gynecol 2004;23:535-545. [PubMed: 15170792]

63. DeVore GR, Polanco B, Sklansky MS, Platt LD. The 'spin' technique: a new method for examination of the fetal outflow tracts using three-dimensional ultrasound. Ultrasound Obstet Gynecol 2004;24:72-82. [PubMed: 15229920] 
64. Espinoza J, Goncalves LF, Lee W, et al. The use of the minimum projection mode in 4-dimensional examination of the fetal heart with spatiotemporal image correlation. J Ultrasound Med 2004;23:1337-1348. [PubMed: 15448324]

65. Goncalves LF, Espinoza J, Lee W, Mazor M, Romero R. Three- and four-dimensional reconstruction of the aortic and ductal arches using inversion mode: a new rendering algorithm for visualization of fluid-filled anatomical structures. Ultrasound Obstet Gynecol 2004;24:696-698. [PubMed: 15521086]

66. Goncalves LF, Espinoza J, Romero R, et al. A systematic approach to prenatal diagnosis of transposition of the great arteries using 4-dimensional ultrasonography with spatiotemporal image correlation. J Ultrasound Med 2004;23:1225-1231. [PubMed: 15328439]

67. Goncalves LF, Romero R, Espinoza J, et al. Four-dimensional ultrasonography of the fetal heart using color Doppler spatiotemporal image correlation. J Ultrasound Med 2004;23:473-481. [PubMed: 15098864]

68. Sklansky MS, DeVore GR, Wong PC. Real-time 3-dimensional fetal echocardiography with an instantaneous volume-rendered display: early description and pictorial essay. J Ultrasound Med 2004;23:283-289. [PubMed: 14992367]

69. Espinoza J, Goncalves LF, Lee W, Mazor M, Romero R. A novel method to improve prenatal diagnosis of abnormal systemic venous connections using three- and four-dimensional ultrasonography and 'inversion mode'. Ultrasound Obstet Gynecol 2005;25:428-434. [PubMed: 15846761]

70. Goncalves LF, Espinoza J, Lee W, et al. A new approach to fetal echocardiography: digital casts of the fetal cardiac chambers and great vessels for detection of congenital heart disease. J Ultrasound Med 2005;24:415-424. [PubMed: 15784759]

71. Herberg U, Goldberg H, Breuer J. Three- and four-dimensional freehand fetal echocardiography: a feasibility study using a hand-held Doppler probe for cardiac gating. Ultrasound Obstet Gynecol 2005;25:362-371. [PubMed: 15761914]

72. Vinals F, Mandujano L, Vargas G, Giuliano A. Prenatal diagnosis of congenital heart disease using four-dimensional spatio-temporal image correlation (STIC) telemedicine via an Internet link: a pilot study. Ultrasound Obstet Gynecol 2005;25:25-31. [PubMed: 15593355]

73. Yagel S, Valsky DV, Messing B. Detailed assessment of fetal ventricular septal defect with 4D color Doppler ultrasound using spatio-temporal image correlation technology. Ultrasound Obstet Gynecol 2005;25:97-98. [PubMed: 15690557]

74. DeVore GR, Polanko B. Tomographic ultrasound imaging of the fetal heart: a new technique for identifying normal and abnormal cardiac anatomy. J Ultrasound Med 2005;24:1685-1696. [PubMed: 16301725]

75. Goncalves LF, Espinoza J, Romero R, et al. Four-dimensional ultrasonography of the fetal heart using a novel Tomographic Ultrasound Imaging display. J Perinat Med 2006;34:39-55. [PubMed: 16489885]

76. Leung KY, Ngai CS, Chan BC, et al. Three-dimensional extended imaging: a new display modality for three-dimensional ultrasound examination. Ultrasound Obstet Gynecol 2005;26:244-251. [PubMed: 16116563]

77. Yagel S, Cohen SM, Achiron R. Examination of the fetal heart by five short-axis views: a proposed screening method for comprehensive cardiac evaluation. Ultrasound Obstet Gynecol 2001;17:367369. [PubMed: 11380958]

78. Carvalho JS. Fetal echocardiography. A sophisticated tool in obstetrics. Minerva Cardioangiol 2005;53:129-138. [PubMed: 15986007]

79. Allan LD, Tynan MJ, Campbell S, Wilkinson JL, Anderson RH. Echocardiographic and anatomical correlates in the fetus. Br Heart J 1980;44:444-451. [PubMed: 7426207]

80. Sharland GK, Allan LD. Screening for congenital heart disease prenatally. Results of a $21 / 2$-year study in the South East Thames Region. Br J Obstet Gynaecol 1992;99:220-225. [PubMed: 1606121]

81. Stephens JD. Accuracy of apical four-chamber view as screen for congenital heart disease. Am J Obstet Gynecol 1990;163:249-250. [PubMed: 2197868]

82. Allan LD, Crawford DC, Chita SK, Tynan MJ. Prenatal screening for congenital heart disease. Br Med J (Clin Res Ed) 1986;292:1717-1719. 
83. DeVore GR. The prenatal diagnosis of congenital heart disease--a practical approach for the fetal sonographer. J Clin Ultrasound 1985;13:229-245. [PubMed: 3923046]

84. Gembruch U, Knopfle G, Chatterjee M, et al. Prenatal diagnosis of atrioventricular canal malformations with up-to-date echocardiographic technology: report of 14 cases. Am Heart J 1991;121:1489-1497. [PubMed: 2017980]

85. McGahan JP. Sonography of the fetal heart: findings on the four-chamber view. AJR Am J Roentgenol 1991;156:547-553. [PubMed: 1899755]

86. Shultz SM, Pretorius DH, Budorick NE. Four-chamber view of the fetal heart: demonstration related to menstrual age. J Ultrasound Med 1994;13:285-289. [PubMed: 7932993]

87. Ultrasonography in pregnancy. Obstet Gynecol 2004;104:1449-1458. [PubMed: 15572512]ACOG Practice Bulletin No. 58

88. American Institute of Ultrasound In Medicine. AIUM Practice Guideline for the Performance of an Antepartum Obstetric Ultrasound Examination. (Pamphlet, 2003).

89. American College of Radiology. ACR practice guideline for the performance of antepartum obstetrical ultrasound. 2004:689-695.

90. Chaoui R. The four-chamber view: four reasons why it seems to fail in screening for cardiac abnormalities and suggestions to improve detection rate. Ultrasound Obstet Gynecol 2003;22:3-10. [PubMed: 12858294]

91. Leung MP, Tang MH, Ghosh A. Prenatal diagnosis of congenital heart malformations: classification based on abnormalities detected by the four-chamber view. Prenat Diagn 1999;19:305-313. [PubMed: 10327133]

92. Abuhamad AZ. Standardization of 3-dimensional volumes in obstetric sonography: a required step for training and automation. J Ultrasound Med 2005;24:397-401. [PubMed: 15784757] 


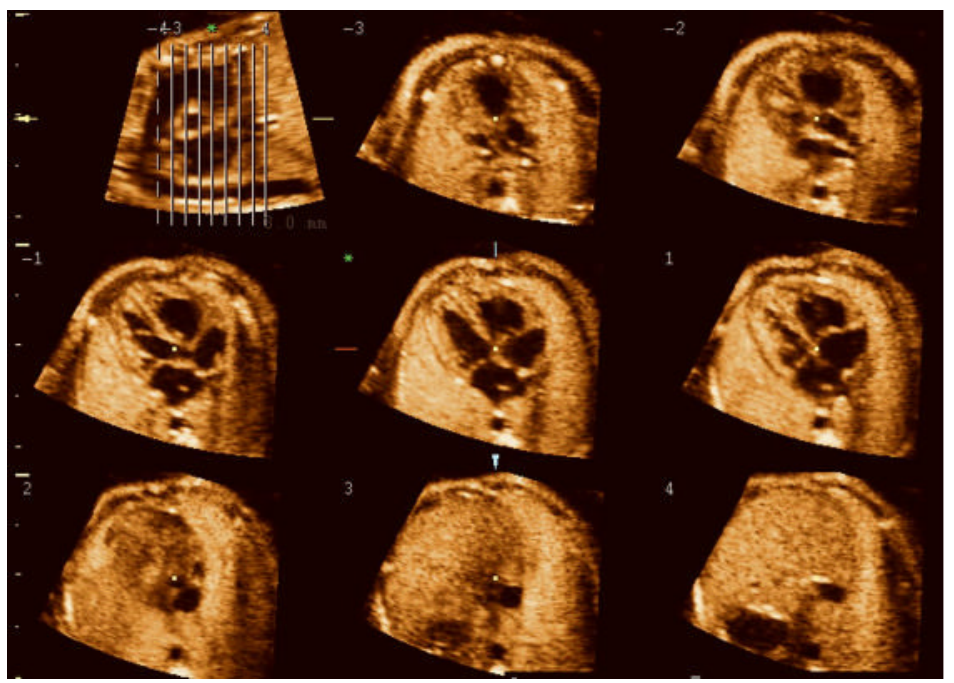

Figure 1.

An "overview image" is shown on the upper left corner. The parallel lines determine the position of the eight orthogonal planes to the plane containing the "overview image". 


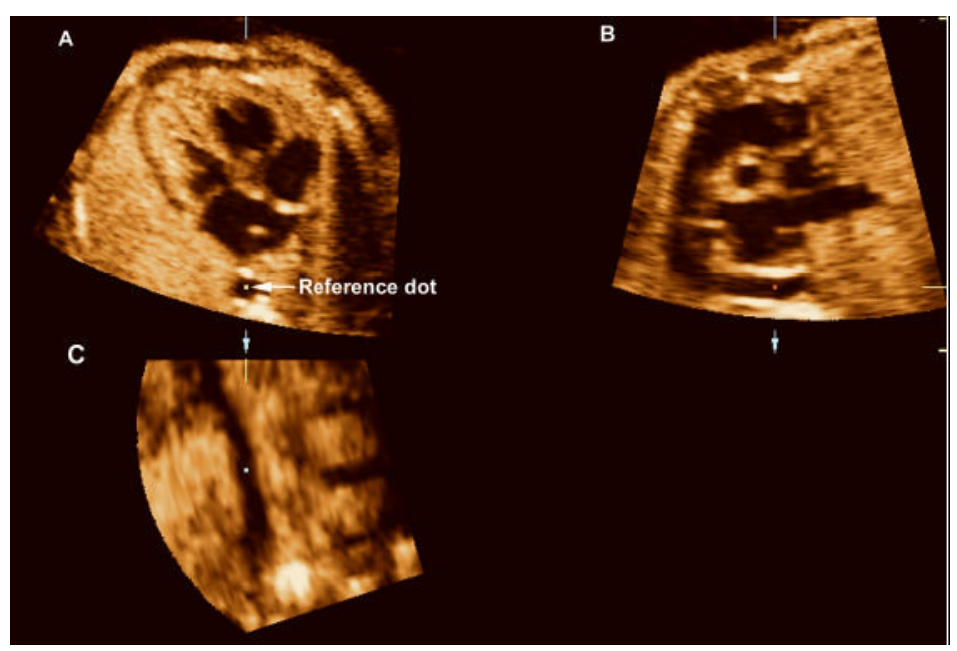

Figure 2.

Volume datasets were adjusted to display the four chamber view in panel A, where the fetal aorta was aligned with the crux of the heart in the vertical plane. The reference dot was positioned in the aorta allowing the visualization of the coronal view of the descending aorta in panel $\mathrm{C}$. 


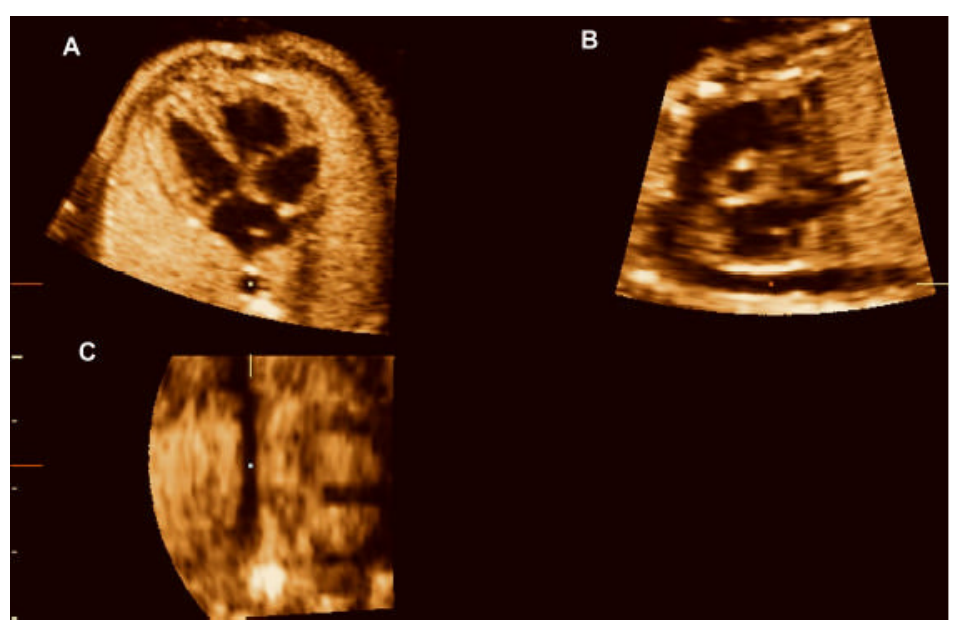

Figure 3.

In panel $\mathrm{C}$ the image was rotated to display the aorta in a vertical position, when necessary. This allowed for the visualization of the longitudinal view of the ductal arch in panel B. 


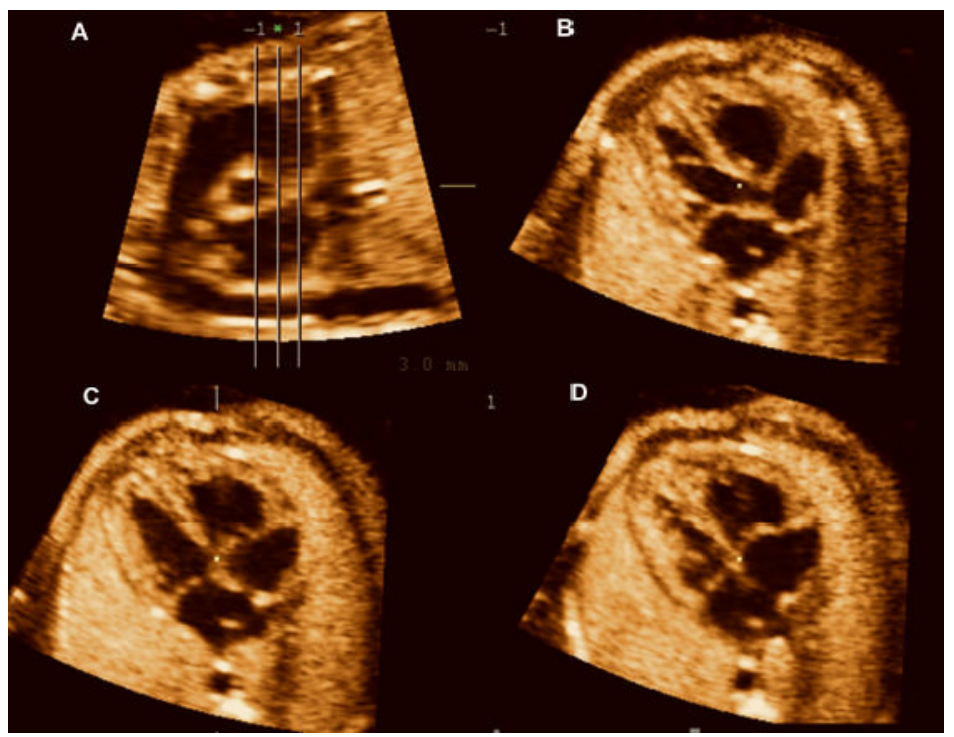

Figure 4.

Only three planes were selected, using the "Slices" option, including the plane that crosses the reference dot (which is labeled with an asterisk in the software), one plane to the left ("-1") and one to the right ("+ 1 ") to the plane crossing the reference dot. These images were magnified using the four panel "Display format". 


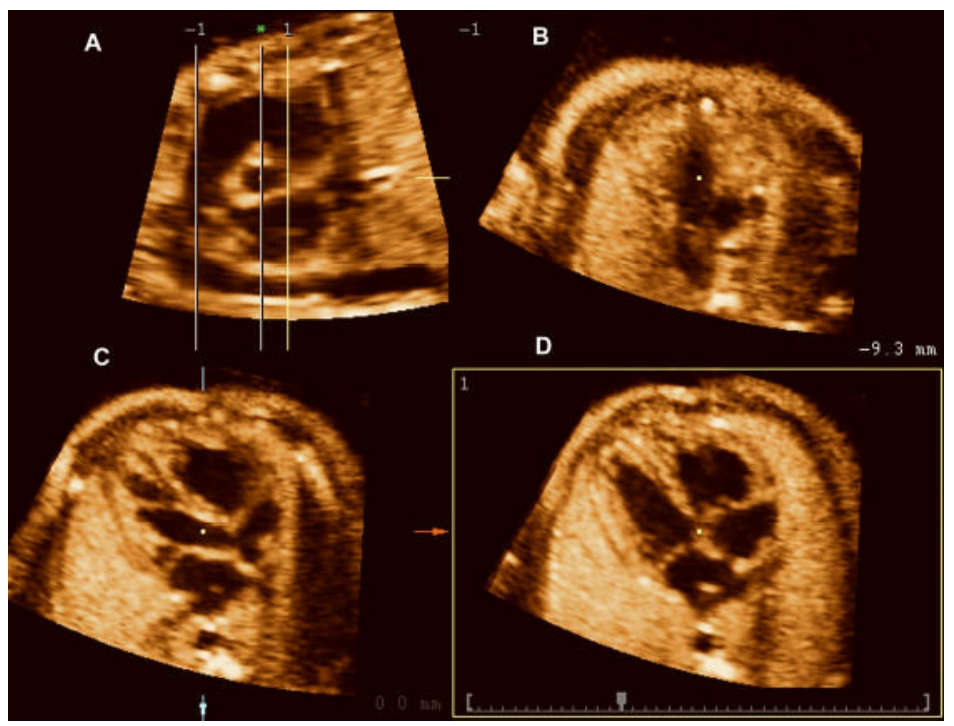

Figure 5.

In panel A, the image was moved until the reference dot was positioned in the center of the aorta. The "Adjust" option was selected to align the "-1" plane with the ductal arch and the " +1 " plane with the external edge of the aorta. This allowed for the simultaneous visualization of the ductal arch in panel A, the three-vessel and trachea view in panel B, the five chamber view in panel $\mathrm{C}$ and the four chamber view in panel $\mathrm{D}$. 


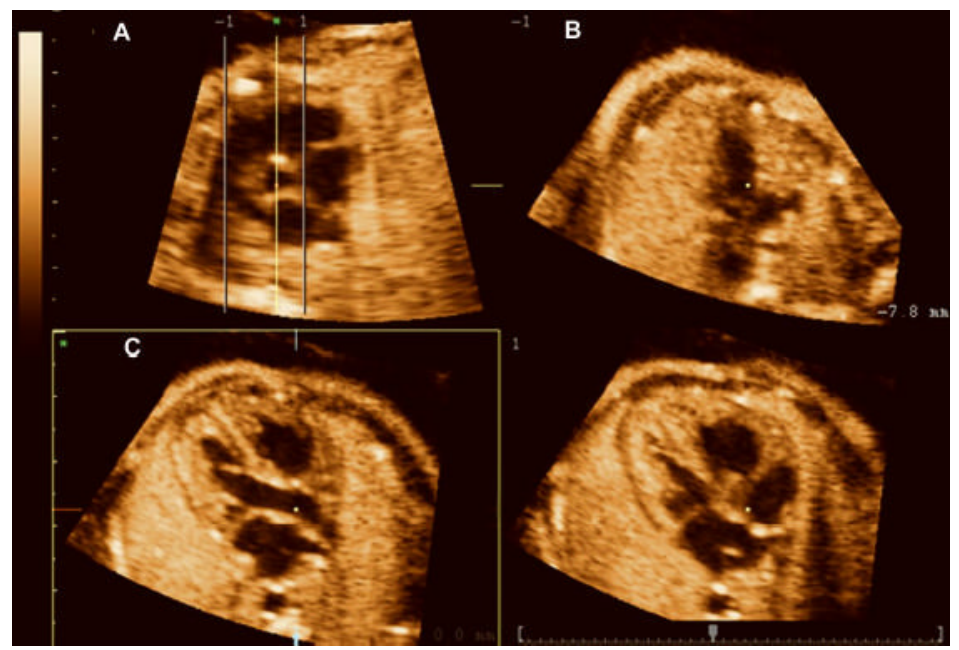

Figure 6.

The "Rotation Y" was selected by clicking on the bar, and the five chamber view was rotated by scrolling on the $\mathrm{Y}$ axis until the left outflow tract was visualized in panel $\mathrm{B}$. This allowed for the simultaneous visualization of the short axis of the aorta in panel A, the three vessel and trachea view in panel $\mathrm{B}$, the long axis of the left outflow tract on panel $\mathrm{C}$ and the four chamber view on panel D 
Table 1

Visualization rates of normal fetal echocardiographic planes using B-Mode and color Doppler in volume datasets from fetuses without heart defects

\begin{tabular}{lcc}
\hline Echocardiographic plane & B-Mode $(\mathbf{n}=\mathbf{1 1 5})$ & Color Doppler $(\mathbf{n}=\mathbf{8 0})$ \\
\hline Four-chamber view & $100(115 / 115)$ & $97.5(78 / 80)$ \\
Five-chamber view & $95.7(110 / 115)$ & $98.8(79 / 80)$ \\
Three-vessels and trachea view & $82.6(95 / 115)$ & $96.3(77 / 80)$ \\
Longitudinal view of the ductal arch & $97.4(112 / 115)$ & $100(80 / 80)$ \\
Long axis view of the left outflow tract $_{* *}$ & $91.3(105 / 115)$ & $96.3(77 / 80)$ \\
Short axis view of the aorta $^{*}$ & $84.3(97 / 115)$ & $91.3(73 / 80)$ \\
Simultaneous visualization $^{*}$ & $71.3(82 / 115)$ & $87.5(70 / 80)$ \\
\end{tabular}

Data expressed and percentages and proportions. NS: not significant

* Simultaneous visualization of the three-vessel and trachea view, four-chamber view, and both outflow tracts

***ight outflow tract 
Table 2

Visualization rates of fetal echocardiographic planes according to gestational age among fetuses without heart defects

\begin{tabular}{|c|c|c|c|c|c|}
\hline Echocardiographic plane & $<20$ weeks $(n=42)$ & $\begin{array}{c}20 \text { to } 30 \text { weeks } \\
(n=120)\end{array}$ & $\mathrm{p}^{a}$ & $>30$ weeks $(n=33)$ & $\mathrm{p}^{b}$ \\
\hline Four-chamber view & $97.6(41 / 42)$ & $99.2(119 / 120)$ & NS & $100(33 / 33)$ & NS \\
\hline Five-chamber view & $90.5(38 / 42)$ & $99.2(119 / 120)$ & 0.02 & $97(32 / 33)$ & NS \\
\hline Three-vessels and trachea view & $83.3(35 / 42)$ & $89.2(107 / 120)$ & NS & $90.9(30 / 33)$ & NS \\
\hline Longitudinal view of the ductal arch & $97.6(41 / 42)$ & $98.3(118 / 120)$ & NS & $100(33 / 33)$ & NS \\
\hline $\begin{array}{l}\text { Long axis view of the left outflow } \\
\text { tract }\end{array}$ & $88.1(37 / 42)$ & $94.2(113 / 120)$ & NS & $97(32 / 33)$ & NS \\
\hline Short axis view of the aorta $* *$ & $88.1(37 / 42)$ & $85.8(103 / 120)$ & NS & $90.9(30 / 33)$ & NS \\
\hline Simultaneous visualization $*$ & $69(29 / 42)$ & $79.2(95 / 120)$ & NS & $84.8(28 / 33)$ & NS \\
\hline
\end{tabular}

Data expressed and percentages and proportions. NS: not significant.

* Simultaneous visualization of the three-vessel and trachea view, four-chamber view, and both outflow tracts

***ight outflow tract

$p^{a}$ comparison between volume datasets from fetuses at <20 weeks of gestational age and those from fetuses between 20-30 weeks of gestation. $p^{b}$ comparison between volume datasets from fetuses between 20-30 weeks of gestation and those from fetuses at $>30$ weeks of gestational age. 
Table 3

Visualization rates of fetal echocardiographic planes using B-Mode and color Doppler in volume datasets from fetuses with heart defects

\begin{tabular}{lrr}
\hline Echocardiographic plane & B-Mode $(\mathbf{n}=\mathbf{1 1})$ & Color Doppler $(\mathbf{n = 9})$ \\
\hline Four-chamber view & $81.8(9 / 11)$ & $88.9(8 / 9)$ \\
Five-chamber view & $72.7(8 / 11)$ & $88.9(8 / 9)$ \\
Three-vessels and trachea view & $63.6(7 / 11)$ & $44.4(4 / 9)$ \\
Longitudinal view of the ductal arch & $72.7(8 / 11)$ & $55.6(5 / 9)$ \\
Long axis view of the left outflow tract & $54.5(6 / 11)$ & $55.6(5 / 9)$ \\
Short axis view of the aorta & NS & $66.7(6 / 9)$ \\
Simultaneous visualization $^{*}$ & $72.7(8 / 11)$ & $33.3(3 / 9)$ \\
\end{tabular}

Data expressed and percentages and proportions. NS: not significant.

* Simultaneous visualization of the three-vessel and trachea view, four-chamber view, and both outflow tracts

***ight outflow tract 